\title{
Movements of the stomach compartments of a young bull during sucking
}

\author{
By R. N. B. KAY* AND Y. RUCKEBUSCH \\ Laboratoire de Physiologie, Therapeutique et Pharmacodynamie, \\ Ecole Nationale Vétérinaire, Toulouse, France
}

(Received 8 December 1970-Accepted I I March I97I)

\begin{abstract}
I. Gastric motility was studied in a young bull and two sheep which had retained their sucking behaviour. Pressure tracings or electromyograms were recorded from all compartments of the stomach.

2. During the sucking of milk or water reticulum contractions either became more frequent but weak, or ceased altogether. After sucking, or after the introduction of fluid directly into the abomasum, reticulum contractions slowed down but retained their strength. The rumen and omasum were more fully inhibited than the reticulum.

3. It is concluded that the inhibitory response to sucking has two phases, a cephalic phase dependent upon the eagerness of sucking which mainly influences the strength of the contractions of the forestomach, and an abomasal phase dependent on the degree of distension of the abomasum which mainly affects the frequency of the contractions.
\end{abstract}

When young mammals suck their dam a behaviour pattern is evoked which is quite different from that seen during drinking to relieve thirst. In young ruminants closure of the oesophageal groove is a component of sucking behaviour and ensures that milk is channelled directly to the abomasum, instead of entering the forestomach. When the sucking animal starts to eat solid food the forestomach rapidly develops and assumes its function as a fermentation chamber (Warner \& Flatt, 1965). A lamb normally loses its sucking behaviour soon after being separated from its mother, but if it is trained to suck milk or other fluids from a bottle or pail sucking can be retained well into adult life (Watson, I944; Ørskov \& Benzie, ı969; Ørskov, Benzie \& Kay, 1970).

In such an animal it is possible to record during sucking the complex and vigorous movements of the mature forestomach. The experiments we now describe were made on a young bull with retained sucking behaviour; supplementary observations were made on two sheep. Inhibition of all compartments of the forestomach was recorded during sucking, a response differing entirely from that seen during drinking. A brief report has been published (Kay \& Ruckebusch, 197I).

\section{EXPERIMENTAL}

\section{Animals}

Most observations were made on an uncastrated bull of the Aubrac breed. It was between 12 and 15 months old during the period of the experiment and weighed about $200 \mathrm{~kg}$. It ran with its dam at pasture until 5 months old, remained at pasture alone for

\footnotetext{
* Present address: Rowett Research Institute, Bucksburn, Aberdeen AB 2 9SB.
} 
another 3 months and was then housed indoors where it was given hay ad lib. plus about I $\mathrm{kg}$ concentrates daily. When first housed it was encouraged to suck 21 of warm (about $37^{\circ}$ ) reconstituted full-cream cow's milk from a watering-can whose spout was fitted with a large teat. After a week it began to suck enthusiastically from the can. It was subsequently given the milk twice weekly. Drinking water was freely available.

When the bull was 12 months old a fistula was prepared in the dorsal sac of the rumen and fitted with a cannula $8 \mathrm{~cm}$ in diameter. At a second operation, 3 weeks later, stainless-steel electrodes were implanted on the serosal surfaces of the right side of the reticulum, the left side of the main dorsal sac of the rumen, the lower part of the greater curvature of the omasum, and the pyloric antrum. The technique was similar to that described by Ruckebusch (1970)

Two ewes of the Charmoise breed were also used. They were 6 and 8 months old at the start of the experiment and weighed about 20 and $30 \mathrm{~kg}$ respectively. They had been separated from their dams when 6 weeks old and trained to suck reconstituted milk, $0.5 \mathrm{l} / \mathrm{d}$, from a nipple-bottle. They received a pelleted hay-concentrate diet ad lib. and water was freely available. At the beginning of the experimental period the oesophagus was catheterized so that suspensions of barium sulphate (Damancy Micropaque) could be injected directly into the thoracic oesophagus (Ørskov et al. 1970). Subsequent radioscopy showed whether the barium passed to the abomasum or ruminoreticulum and thus whether the oesophageal groove was closed or not at the time of injection. Electrodes were implanted on the serosal surface of the ventral reticulum, and on the lateral aspect of the fundus and pyloric antrum of the abomasum. A rumen cannula $5 \mathrm{~cm}$ in diameter was inserted into one of the sheep and a $2 \mathrm{~mm}$ plastic catheter was sewn into the fundus of its abomasum.

\section{Records}

The electrical activity of the stomach muscle was registered with pen recorders (Ruckebusch, 1970). In the bull, movements and pressure changes at various positions within the stomach were recorded by use of water-filled balloons attached to pressure transducers. These were placed at the bottom of the reticulum and in the atrium, the posterior dorsal sac and the main ventral sac of the rumen. Further details are given by Ruckebusch \& Kay (1971).

RESULTS

\section{The bull}

Gastric motility when not sucking. The electrical activity and pressure changes recorded from the ruminoreticulum and omasum while the bull was feeding, ruminating or at rest are described elsewhere (Ruckebusch \& Kay, 1971). The activity at rest may be seen in the first parts of Figs. 2-5.

The effects of drinking $\operatorname{cool}\left(20^{\circ}\right)$ water from a trough are shown in Fig. I. The bull had been deprived of water overnight. There was a slight acceleration of the cyclical electrical activity of the reticulum during the period of drinking without any notable 
change in its intensity. The slow discharge of the omasum and fast rhythmic discharge of the pyloric antrum were quite unaffected.

Gastric motility when sucking. Fig. 2 shows the pattern of gastric motility observed while the bull sucked 21 of warm milk from the watering-can. The major contractions of the ruminoreticulum and the electrical discharge from the dorsal sac of the rumen and the omasum ceased altogether during the $2.5 \mathrm{~min}$ period of sucking. They started again subsequently in the order reticulum, omasum, dorsal sac and lastly ventral sac, but their frequency was less than normal for the next Io min.

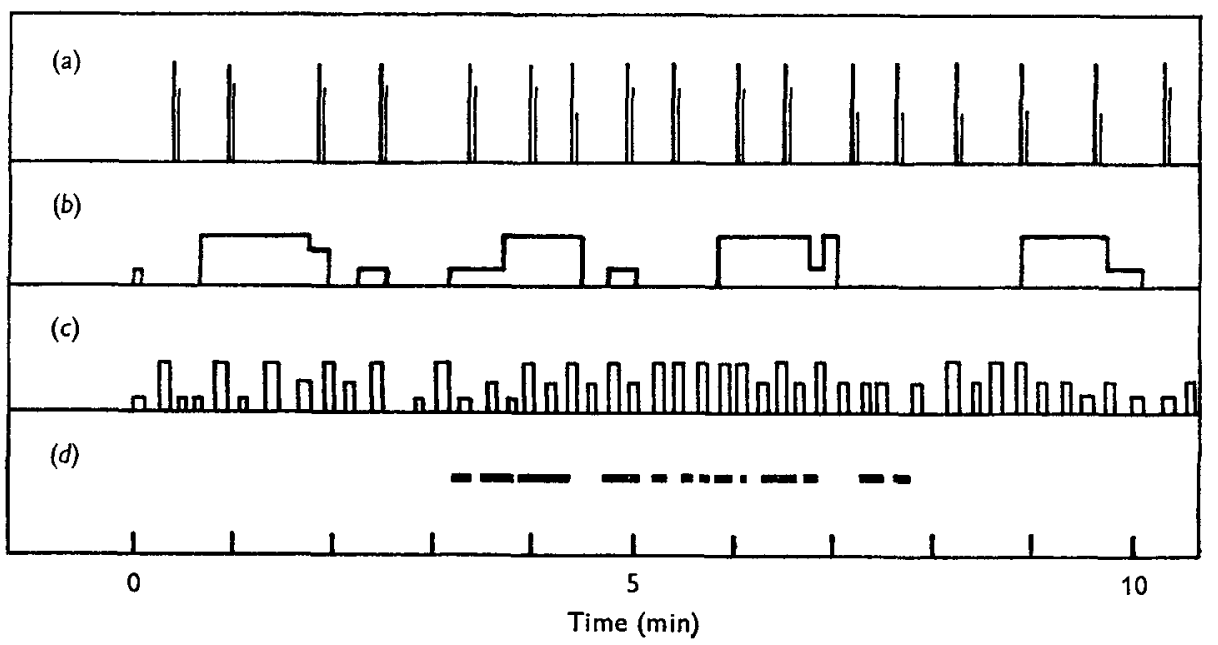

Fig. I. Bull. Diagrammatic representation of electromyograms recorded from $(a)$, the reticulum; $(b)$, the omasum and $(c)$, the pyloric antrum during the drinking of cold water. The straight lines $(d)$ indicate the duration of drinking. The height of records $a, b$ and $c$ indicates approximately the intensity of the electromyogram.

Fig. 3 shows the effect of sucking 21 of tepid water; the trial was made 45 min before that shown in Fig. 2. The activity of the rumen and omasum ceased, as when milk was sucked, but on this occasion the contractions of the reticulum were only slightly affected. On other days partial or complete inhibition of reticulum contractions was seen when water was sucked.

The animal seldom sucked water as avidly as milk. In some trials a hand was inserted through the rumen fistula before sucking to test whether any of the swallowed fluid could be felt to pass into the rumen. This could never be detected when milk was sucked but water could often be felt to escape from the oesophageal groove in substantial amounts.

The electromyogram from the abomasum shows rapid cyclical activity which waxes and wanes over a period of about an hour (Ruckebusch, 1970; Ruckebusch \& Kay, 1971). Sucking milk usually increased this activity immediately, if it were not already vigorous, and made it more continuous. Afterwards there was usually a long period of strong cyclical activity, though sometimes the activity became irregular and declined.

Ruminoreticular inhibition: cephalic and abomasal phases. Important variations in the response to sucking could be demonstrated, which made it clear that the inhibitory 
(a)

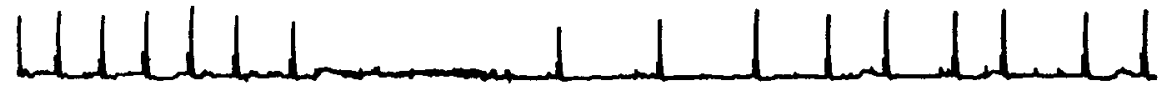

(b)

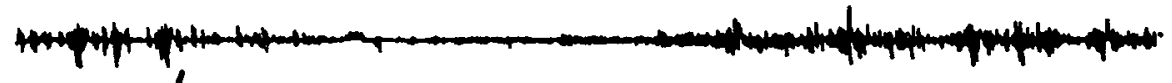

(c)

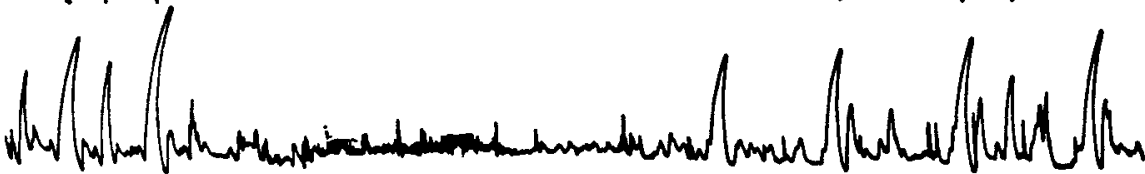

(d)

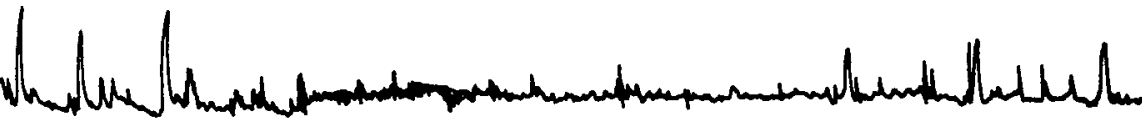

(e)

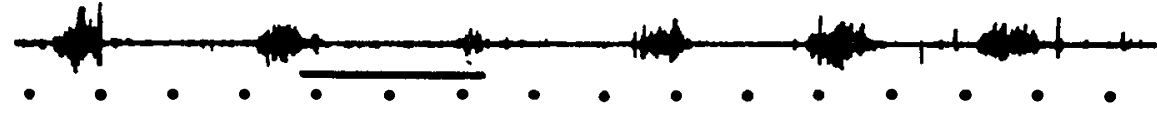

Fig. 2. Bull. The effects of sucking 21 of warm milk on gastric motility. Records: (a), pressure change in the reticulum; $(b)$, electromyogram from the dorsal sac of the rumen; $(c)$, pressure change in the posterior dorsal sac of the rumen; $(d)$, pressure change in the ventral sac of the rumen; (e), electromyogram from the omasum; $(f)$, time in min. The straight line indicates the duration of sucking. Artifacts caused by excited movements and coughing during sucking have been erased for the sake of clarity.

(a)

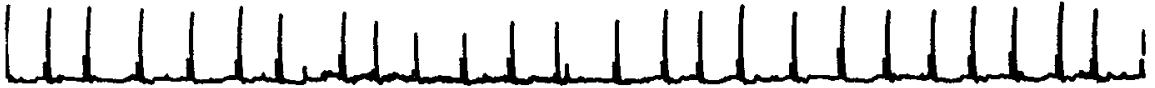

(b)

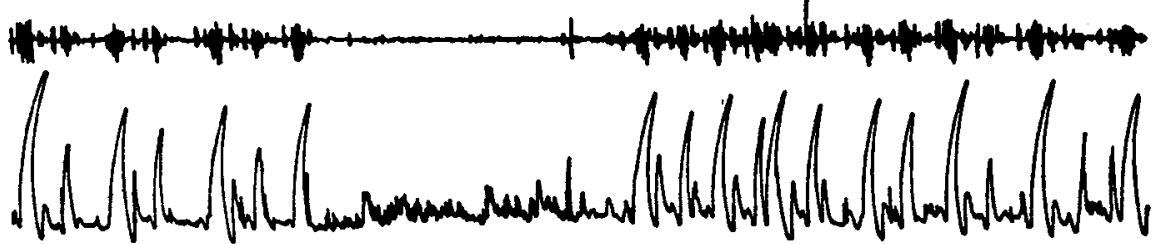

(d)

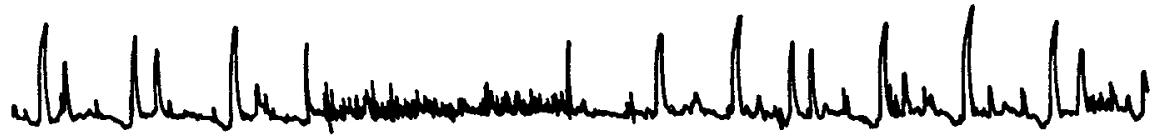

(e)



Fig. 3. Bull. The effects of sucking 21 of tepid water. Records are as in Fig. 2. The trial was made 45 min before that illustrated in Fig. 2. 
effect seen during sucking was of quite a different nature to that seen immediately afterwards.

During sucking the reticulum often remained active for one or two cycles of increased frequency but progressively diminishing intensity. This was clearly seen in the electromyogram, and pressure tracings showed a corresponding change when not obscured by movements of the animal. The rumen was more fully inhibited and a parallel graded inhibition was not clearly evident. The extent of inhibition of the forestomach as a whole seemed to depend on how keenly the animal sucked the fluidoffered

(a)

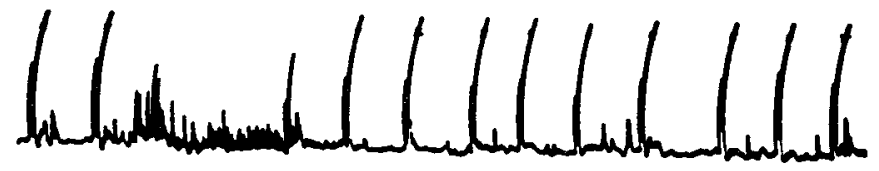

(b)

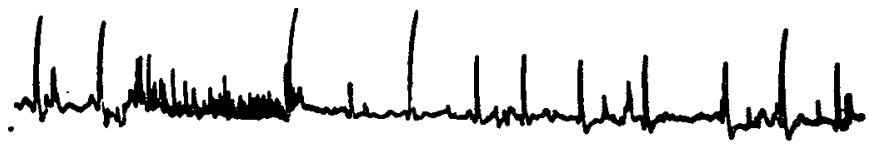

(c)

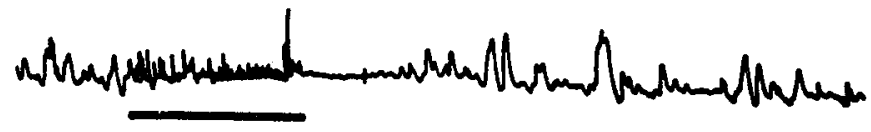

II

(a)

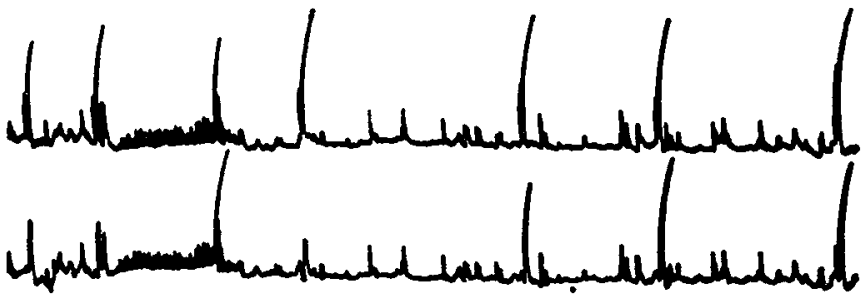

(c)

(d)

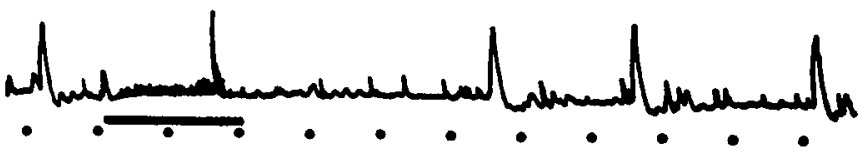

Fig. 4. Bull. Two responses (records I and II) to sucking 21 of warm milk, indicated by the straight lines. Records: $(a)$, pressure changes in the reticulum; $(b)$, in the atrium and (c), in the posterior dorsal sac of the rumen; $(d)$, time in min. Part II starts $45 \mathrm{~min}$ after I, and $15 \mathrm{~min}$ after 21 of milk had been introduced by tube into the abomasum. The small rapid pressure fluctuations seen during sucking were associated with swallowing, the larger irregular fluctuations with movements of the animal or, towards the end of each period, with coughing.

(compare Figs. 2 and 3). The volume consumed seemed unimportant in this phase of inhibition except in that it determined the duration of sucking and of inhibition. Very similar responses to sucking 0.51 and 2.01 of milk could be obtained if the smaller volume were given slowly so that the animal sucked for the same length of time in each instance. Fig. 6 illustrates some of these points as they affected the sheep.

The inhibition observed after the end of sucking differed in that when the contrac- 
tions resumed they had about their normal intensity but a diminished frequency, and in that the degree of inhibition did depend on the volume of fluid consumed. Fig. 4 shows two responses to sucking 21 of milk. The bull consumed the first 21 offered (Fig. $4 \mathrm{I}$ ) in $2.5 \mathrm{~min}$ and the reticulum, atrium and posterior dorsal sac of the rumen were completely inhibited while he sucked. Almost immediately afterwards they began to contract again at their normal frequency. After $30 \mathrm{~min} 2 \mathrm{l}$ of milk were introduced into the abomasum by means of a tube inserted through the reticulo-omasal orifice. Fifteen minutes later (Fig. 4II) 21 of milk were again sucked from the can. This was taken as eagerly as before and ruminoreticular activity was again inhibited, but this time a prolonged inhibitory effect was seen after the end of sucking.

(a)

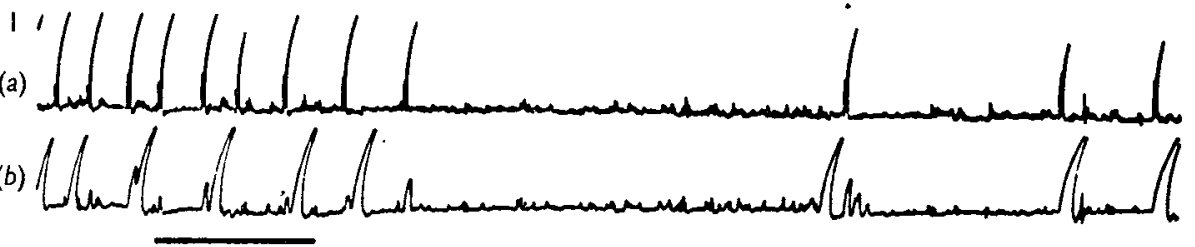

II
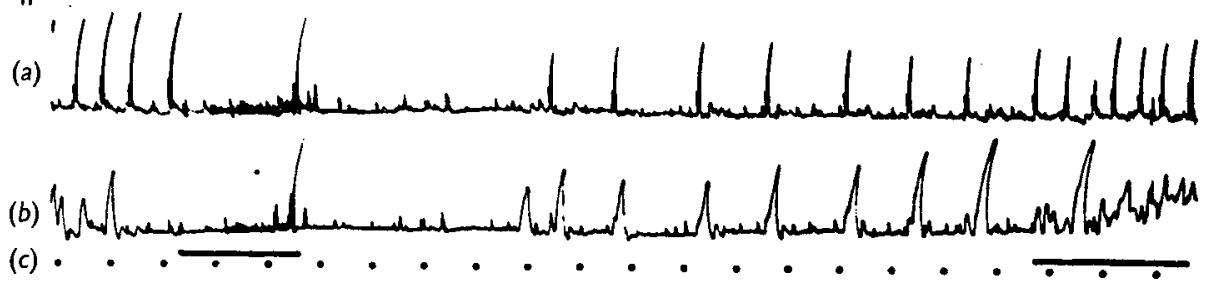

Fig. 5. Bull. Responses to (I) the introduction of 21 of warm milk into the abomasum by a tube inserted through the reticulo-omasal orifice and (II) the sucking of 21 of milk. The straight lines on the left indicate the duration of these procedures. Records: pressure changes $(a)$, in the reticulum and $(b)$, in the posterior dorsal sac of the rumen; $(c)$, time in min. The large pressure fluctuation seen at the end of sucking was caused by a cough. The bull was allowed to eat pelleted food at the end of period II (straight line on the right).

Fig. 5 compares the response to addition of 21 of milk to the abomasum by tube with that to sucking the same volume. An interval of $2.5 \mathrm{~h}$ was allowed between the trials to diminish any persisting effect of abomasal distension. The introduction of milk by tube (Fig. 5 I) had little immediate effect on the movements of the forestomach but produced a marked inhibition afterwards; in this instance contractions ceased altogether for 8 min. On the other hand, the sucking of milk (Fig. 5 II) was accompanied by complete inhibition but there was a less marked inhibition afterwards. On other occasions it was found that warm water introduced into the abomasum by tube had just the same inhibitory effects as milk, depending only on the cumulative volume of fluid given.

Repeated additions of fluid to the abomasum caused no sign of distress. The bull would readily suck milk from the can or eat food even when 101 of fluid had been sucked or introduced into the abomasum over a period of $3 \mathrm{~h}$. If he was allowed to eat while his forestomach was somewhat inhibited the contractions were greatly 
accelerated (Figs. 5II and 6IV), but when the food was removed the inhibition reasserted itself.

The bull became excited whenever he saw his usual attendant, especially if holding the watering-can. His heart rate usually doubled and he eagerly reached out towards the can. If the can were withheld for I or 2 min there was often a slight increase in the frequency of forestomach contractions but no consistent change in their magnitude.

\section{The sheep}

The responses of the stomach compartments of the two sheep were very like those seen in the bull. The drinking of 0.51 of cool water caused, at most, a slight acceleration of reticulum contractions.
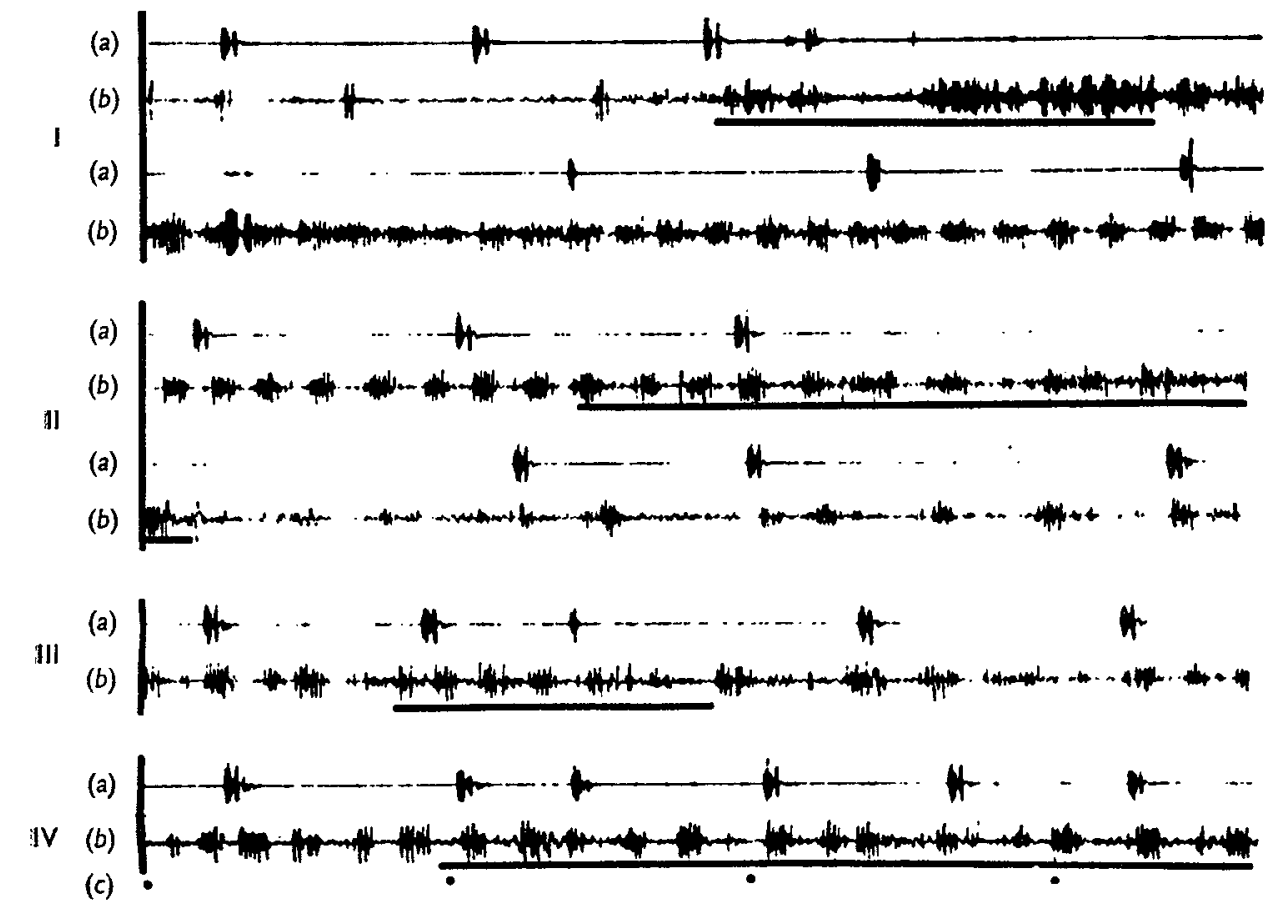

Fig. 6. Sheep. Responses to (I), sucking 0.51 of warm milk; (II), introduction of 0.51 of milk into the abomasum by catheter; (III), sucking O. I l of milk, given slowly, and (IV), eating pelleted food. Records : electromyograms from $(a)$, the reticulum and $(b)$, the fundus of the abomasum; (c), time in min. The straight lines indicate the duration of these procedures. The upper and lower pairs of records run continuously in I and in II.

Fig. 6 shows some examples of responses of the reticulum and abomasum to sucking, recorded electromyographically. The sucking of 0.51 of milk from a bottle (Fig. 6I) briefly increased the frequency of reticular activity but so reduced its intensity that it soon disappeared altogether; on other occasions frequent low-intensity contractions persisted throughout the period of sucking. Abomasal activity was greatly increased. Injection of 0.51 of milk into the abomasum (Fig. 6II), 24 min later, had a less immediate effect, slowing the contractions without affecting their intensity. It also 
disturbed and then reduced the rhythmic activity of the abomasum. Sixteen minutes afterwards (Fig. 6III) the sheep was allowed to suck 0.11 of milk slowly. The inhibitory response of the reticulum during sucking was similar to that seen when 0.51 was given but the contractions resumed with undiminished frequency immediately afterwards. Feeding (Fig. 6IV) $8 \mathrm{~min}$ later stimulated the reticulum but not the abomasum.

In other experiments warm water was given by bottle, from which it was sucked as eagerly as milk, or by injection into the abomasum; the inhibitory effects were much the same as those seen when milk was given. Injection of 0.51 of warm water or milk into the rumen, by way of the rumen cannula, produced no appreciable response.

The sheep became very excited and their heart rate increased greatly whenever an attendant approached them with a bottle. Reticulum activity usually increased slightly in frequency but its intensity was unchanged. If barium sulphate was injected into the oesophagus while the sheep was teased with the bottle, radioscopy showed that it passed to the ruminoreticulum. If it was mixed with the milk or water sucked from the bottle it passed to the abomasum.

\section{DISCUSSION}

Inhibition of ruminoreticular contractions during sucking was first reported, rather briefly, by Schalk \& Amadon (1928). The response, recorded in three unweaned calves and also in an adult cow when licking salt, was always associated with closure of the oesophageal groove. Our observations indicate clearly that the response consists of two phases. During sucking there was a cephalic phase, characterized by accelerated frequency but diminished intensity of reticulum contractions and dependent on the degree of excitement with which the animal sucked. After sucking there was an abomasal phase, characterized by diminished frequency but about normal intensity of reticulum contractions and dependent on the degree of distension of the abomasum. The inhibition of the cephalic phase is therefore mainly inotropic in nature while that of the abomasal phase is mainly chronotropic.

The extent of inhibition of the reticulum during either phase could vary between the barely perceptible, as in Fig. 3, to complete and prolonged, as in Fig. 5. Inhibition of the various compartments of the rumen and the omasum was always more marked than that of the reticulum. The effect of sucking on abomasal activity was less easy to determine, since the normal activity is variable; electrical activity was usually increased but sometimes decreased. In the two sheep there was some evidence that this inconsistent response could result from summation of a stimulatory effect of sucking with an inhibitory effect of abomasal distension.

Our observations were made on only one bull and two sheep. Although the effects of sucking on gastric motility were much the same in all three animals it will clearly be necessary to study a larger group to learn how much variation may occur in this response.

Inhibition of the forestomach by distension of the abomasum is a well-known reflex effect (Titchen, 1968); we have studied it further in adult cattle (Ruckebusch \& Kay, 
I97I). The inhibition seen during the cephalic phase of sucking, like closure of the oesophageal groove, may be a component of the behavioural response to the sucking situation. Further evidence for this would be the demonstration that a similar inhibition occurs during conditioned closure of the groove. But in fact a slight acceleration of the reticulum was seen when the animals were teased with the milk container. However, radioscopy of the sheep showed that the groove did not close during teasing, indicating that the behavioural response to teasing was incomplete. Evidently it was not possible to train the animals sufficiently while frequent experiments were being made. Earlier experiments by Ørskov et al. (1970) had shown that routine management is essential if conditioned closure of the groove is to be obtained consistently. Receptive relaxation (Cannon \& Lieb, I9II) and reflex relaxation (Jansson, 1969) of the stomach have been described in non-ruminant species, but it is uncertain how analogous this loss of tension is to the inhibition of cyclical activity of the ruminant's forestomach.

The patterns of gastric activity recorded in the young bull while feeding and ruminating and when at rest were similar to those seen in two adult cows (Ruckebusch \& Kay, 1971), so there is no reason to suppose there is anything abnormal about the activity seen in adult ruminants which have retained their sucking behaviour. Indeed, in nature young ruminants are suckled by their dams for some months after they have begun to eat herbage and have developed a mature forestomach. The powerful mixing and eructation contractions of the ruminoreticulum are associated with movement and electrical activity of the oesophageal groove (Ruckebusch \& Kay, 197I and unpublished observations). Possibly the functional significance of inhibition of these contractions during sucking is that it prevents any interference with efficient closure of the groove.

We wish to thank L. Bueno, Ingénieur INSA, and P. Guillemot, Docteur-Vétérinaire, for their assistance, and J. Costa and R. Saccareau for care of the animals. One of us (R.N.B.K.) gratefully acknowledges financial support received from the Agricultural Research Council and The Royal Society, London.

\section{REFERENCES}

Cannon, W. B. \& Lieb, C. W. (I91 I). Am. F. Physiol. 20, 267.

Jansson, G. (1969). Acta physiol. scand. 75, 245.

Kay, R. N. B. \& Ruckebusch, Y. (197I). F. Physiol., Lond. 214, 34 P.

Ørskov, E. R. \& Benzie, D. (1969). Br. F. Nutr. 23, 415.

Ørskov, E. R., Benzie, D. \& Kay, R. N. B. (1970). Br. F. Nutr. 24, 785.

Ruckebusch, Y. (1970). F. Physiol., Lond. 210, 857.

Ruckebusch, Y. \& Kay, R. N. B. (197I). Annls Rech. vét. 2, 99.

Schalk, A. F. \& Amadon, R. S. (1928). Bull. N. Dak. agric. Exp. Stn no. 216.

"Titchen, D. A. (1968). In Handbook of Physiology. Section 6: Alimentary Canal Ch. I29 [C. F. Code, editor]. Washington, DC: American Physiological Society.

Warner, R. G. \& Flatt, W. P. (1965). In Physiology of Digestion in the Ruminant p. 24 [R. W. Dougherty, editor]. London: Butterworths.

Watson, R. H. (1944). Bull. Commonw. scient. ind. Res. Org. no. I80, p. I. 